\title{
Effects of yearling, juvenile and adult survival on reef manta ray (Manta alfredi) demography
}

\author{
Isabel M Smallegange ${ }^{\text {Corresp.., }}{ }^{1}$, Isabelle BC van der Ouderaa ${ }^{1}$, Yara Tibiriçá ${ }^{2}$ \\ 1 Institute for Biodiversity and Ecosystem Dynamics, University of Amsterdam, Amsterdam, Netherlands \\ 2 Zavora Marine Lab., Association of Coastal Conservation of Mozambique, Inharrime, Inhambane Province, Mozambique \\ Corresponding Author: Isabel M Smallegange \\ Email address: i.smallegange@uva.nl
}

Background. The trade in manta ray gill plates has considerably increased over the last two decades. The resulting increases in ray mortality, in addition to mortality caused by by-catch, has caused many ray populations to decrease in size. The aim of this study was to ascertain how yearling and juvenile growth and survival, and adult survival and reproduction affect reef manta ray (Manta alfredi) population change, to increase our understanding of manta ray demography and thereby improve conservation research and measures for these fish.

Methods. We developed a population projection model for reef manta rays, and used published life history data on yearling and juvenile growth and adult reproduction to parameterise the model. Because little is known about reef manta ray yearling and juvenile survival, we conducted our analyses using a range of plausible survival rate values for yearlings, juveniles and adults.

Results. The model accurately captured observed variation in population growth rate, lifetime reproductive success and cohort generation time in different reef manta ray populations. Our demographic analyses revealed a range of population consequences in response to variation in demographic rates. For example, an increase in yearling or adult survival rates always elicited greater responses in population growth rate, lifetime reproductive success and cohort generation time than the same increase in juvenile survival rate. The population growth rate increased linearly, but lifetime reproductive success and cohort generation time increased at an accelerating rate with increasing yearling or adult survival rates. Hence, even a small increase in survival rate could increase lifetime reproductive success by one pup, and cohort generation time by several years. Elasticity analyses revealed that, depending on survival rate values of all life stages, the population growth rate is either most sensitive to changes in the rate with which juveniles survive but stay juveniles (i.e. do not mature into adults) or to changes in adult survival rate. However, when assessing these results against estimates on population growth and adult survival rates for populations off the coasts of Mozambique and Japan, we found that the population growth rate is predicted to be always most sensitive to changes in the adult survival rate.

Discussion. It is important to gain an in-depth understanding of reef manta ray life histories, particularly of yearling and adult survival rates, as these can influence reef manta ray population dynamics in a variety of ways. For declining populations in particular, it is crucial to know which life stage should be targeted for their conservation. For one such declining population off the coast of Mozambique, adult annual survival rate has the greatest effect on population growth, and by increasing adult survival by protecting adult aggregation sites, this population's decline could be halted or even reversed. 
1 Effects of yearling, juvenile and adult survival on reef manta ray (Manta alfredi)

2 demography

3

4 Isabel M. Smallegange ${ }^{1}$, Isabelle B.C. van der Ouderaa ${ }^{1}$ and Yara Tibiriçáa

5

$6{ }^{1}$ Institute for Biodiversity and Ecosystem Dynamics, University of Amsterdam, PO Box 94248,

$7 \quad 1090$ GE, Amsterdam, The Netherlands

$8{ }^{2}$ Association of Coastal Conservation of Mozambique, Praia de Zavora, s/n, Inharrime,

9 Inhambane Province, Mozambique

10

11 Corresponding author:

12 Isabel Smallegange

13 Institute for Biodiversity and Ecosystem Dynamics, University of Amsterdam, PO Box 94248,

141090 GE, Amsterdam, The Netherlands

15 Email: i.smallegange@uva.nl 


\section{ABSTRACT}

Background. The trade in manta ray gill plates has considerably increased over the last two decades. The resulting increases in ray mortality, in addition to mortality caused by by-catch, has caused many ray populations to decrease in size. The aim of this study was to ascertain how yearling and juvenile growth and survival, and adult survival and reproduction affect reef manta ray (Manta alfredi) population change, to increase our understanding of manta ray demography and thereby improve conservation research and measures for these fish.

Methods. We developed a population projection model for reef manta rays, and used published life history data on yearling and juvenile growth and adult reproduction to parameterise the model. Because little is known about reef manta ray yearling and juvenile survival, we conducted our analyses using a range of plausible survival rate values for yearlings, juveniles and adults. Results. The model accurately captured observed variation in population growth rate, lifetime reproductive success and cohort generation time in different reef manta ray populations. Our demographic analyses revealed a range of population consequences in response to variation in demographic rates. For example, an increase in yearling or adult survival rates always elicited greater responses in population growth rate, lifetime reproductive success and cohort generation time than the same increase in juvenile survival rate. The population growth rate increased linearly, but lifetime reproductive success and cohort generation time increased at an accelerating rate with increasing yearling or adult survival rates. Hence, even a small increase in survival rate could increase lifetime reproductive success by one pup, and cohort generation time by several years. Elasticity analyses revealed that, depending on survival rate values of all life stages, the population growth rate is either most sensitive to changes in the rate with which juveniles survive but stay juveniles (i.e. do not mature into adults), or to changes in adult 
39 survival rate. However, when assessing these results against estimates on population growth and

40 adult survival rates for populations off the coasts of Mozambique and Japan, we found that the

41 population growth rate is predicted to be always most sensitive to changes in the adult survival

42 rate.

43 Discussion. It is important to gain an in-depth understanding of reef manta ray life histories,

44 particularly of yearling and adult survival rates, as these can influence reef manta ray population

45 dynamics in a variety of ways. For declining populations in particular, it is crucial to know which

46 life stage should be targeted for their conservation. For one such declining population off the

47 coast of Mozambique, adult annual survival rate has the greatest effect on population growth,

48 and by increasing adult survival by protecting adult aggregation sites, this population's decline

49 could be halted or even reversed. 
50

51

52

53

54

\section{INTRODUCTION}

The global demand for animal products such as shark fins (Clarke et al., 2006), swim bladders (Sadovy \& Cheung, 2003; Clark, 2004), and ray gill plates (White et al., 2006; Ward-Paige, Davis \& Worm, 2013) is unsustainable (Berkes et al., 2006; Lenzen et al., 2012). Since 1998, trading in products derived from manta and devil rays has increased exponentially (Ward-Paige, Davis \& Worm, 2013). Ray gill plates are a key ingredient in traditional Chinese medicine, and cartilage serves as a filler in shark fin soup (White et al., 2006; Ward-Paige, Davis \& Worm, 2013). The exploitation of ray species has resulted in population declines (Marshall et al., 2011a; Couturier et al., 2012), and increases their risk of extinction. As a result, some rays, including the reef manta ray Manta alfredi and giant manta ray M. birostris, are now listed as 'Vulnerable' on the International Union for Conservation of Nature (IUCN) Red List of Threatened Species (Marshall et al., 2011a). Reef manta rays have a life history strategy that results in late maturity, a long gestation period and a low mean lifetime reproductive success (Marshall et al., 2011a). Therefore, once a reef manta ray population starts to decrease or contains critically few individuals (e.g. due to overfishing), it is very difficult for the population to recover (Kashiwagi, 2014). Therefore, understanding how manta ray populations' growth rates are affected by variation in demographic rates such as growth, survival and fertility is particularly important (Couturier et al., 2014; Kashiwagi, 2014).

Recently, M. alfredi and M. birostris were listed on Appendix II of the Convention on International Trade in Endangered Species of Wild Fauna and Flora (CITES), meaning that any international trade in manta rays from September 2014 onward must be regulated. However, in many countries, particularly developing ones (e.g. Sri Lanka and countries in East Africa, such as Mozambique), manta ray populations are decreasing at an alarming rate (Marshall et al., 
73 2011a; Ward-Paige, Davis \& Worm, 2013). Although manta ray ecotourism occurs in many of

74 these regions, only in $32 \%$ of them are manta rays protected (Ward-Paige, Davis \& Worm,

75 2013). For example, despite their importance in ecotourism (Tibiriçá et al., 2011), manta rays are

76 not protected under Mozambique law, despite the fact that there has been an $88 \%$ decrease in

77 reef manta ray sightings off Praia do Tofo, Mozambique (Rohner et al., 2013). In addition, the

78 main reef manta ray aggregation areas off the coast of southern Mozambique are not inside

79 marine protected areas (Pereira et al., 2014), and there has been a rapid increase in the use of gill

80 nets by artisanal fisheries within inshore regions that are frequented by the rays, which has

81 significantly increased reef manta ray by-catch (Marshall, Dudgeon \& Bennett, 2011b; Pereira et

82 al., 2014). A comprehensive understanding of reef manta ray demographics, and their responses

83 to different mortality regimes, is therefore urgently needed to improve conservation efforts and

84 management policies (Ward-Paige, Davis \& Worm, 2013).

85 Although manta rays are often easy to approach, we currently do not have sufficient

86 demographic data to fully understand their population dynamics (Ward-Paige, Davis \& Worm,

87 2013). If conservation management policies are to be effective, knowing which age classes

88 (yearlings, juveniles or adults) within a population are the most sensitive to disturbance is

essential. For example, demographic analyses of the population dynamics of other long-lived

90 organisms, such as turtles and killer whales (Orcinus orca), have revealed that population

91 persistence is most sensitive to adult survival, whereas protecting young (e.g. through protective

92 rearing schemes) has a much smaller impact on population persistence (Brault \& Caswell, 1993;

93 Heppell, Crowder \& Crouse, 1996). Therefore, a very small decrease in the annual survival rate

94 of adults likely has serious repercussions on the persistence of populations of long-lived species

95 such as manta rays (Ward-Paige, Davis \& Worm, 2013; Kashiwagi, 2014). 
The aim of this study was to ascertain how yearling and juvenile growth and survival, and

97 adult reproduction and survival, affect populations of reef manta rays. To this end, we developed

a stage-structured population projection model (PPM) (Caswell, 2001) that we parameterised using published life history data obtained from populations off the coasts of southern Mozambique (Marshall, Dudgeon \& Bennett, 2011b) and the Yaeyama Islands, Japan (Kashiwagi, 2014). Sufficient data were available to parameterise growth and reproduction in the PPM, but detailed information on the survival of yearling and juvenile reef manta rays is scarce (Marshall et al., 2011a; Dulvy et al., 2014); therefore, we used the model to investigate how different annual survival rates of yearlings, juveniles and adults affect the population growth rate, mean lifetime reproductive success and cohort generation time. We assessed the performance of the model by comparing the predicted values of these three population biology descriptors with empirical observations. Subsequently, we conducted elasticity analyses for all combinations of yearling, juvenile and adult survival rates to ascertain which demographic rate (rate at which individuals survive and stay in the same life stage; survive and grow into the next life stage; reproduce offspring) of which life stage (yearling, juvenile or adult) has the greatest influence on the population growth rate. Elasticity analysis is widely used by conservation biologists, because the results obtained can be used to prioritise conservation research and management for those life stages that have the greatest effect on population growth (Benton \& Grant, 1999; Carslake, Townley \& Hodgson, 2009). Because much less is known about yearling and juvenile survival rates than adult survival rates (Marshall et al., 2011a; Dulvy et al. 2014), investigating a range of yearling and juvenile survival rates will elucidate if and how reef manta ray population responses vary with variation in survival rates. For all of the combinations of yearling, juvenile and adult survival rates, we used the calculated population growth rates to 
119 project a population of 500 individuals forward over a period of 10 years, in order to investigate

120 the population consequences of different yearling, juvenile and adult mortality regimes.

121

122 METHODS

123 M. alfredi life cycle

124 The life cycle of reef manta rays is generally divided into three life stages: yearlings, non-

125 reproducing juveniles and reproducing adults (Fig. 1) (Marshall et al., 2011a; Kashiwagi, 2014).

126 Male manta rays reach maturity after six years, and females are thought to mature at 8-10 years

127 of age; longevity is estimated to be at least 40 years (Marshall et al., 2011a). On average, adult

128 females produce one pup every two years, but fertility rates can range from one pup every one to

129 five years (Marshall et al., 2011a). Reef manta ray life history data have been collected from

130 various populations, including those off the coasts of Mozambique and the Yaeyama Islands,

131 Japan (Table 1). These two populations differ remarkably in their estimated annual survival rates

132 and population growth rates; the population off the coast of Japan is stable, and juveniles and

133 adults exhibit high survival rates (0.95 per year) (Kashiwagi, 2014), whereas the population off

134 the coast of Mozambique is declining, and the adult survival rate is estimated to be as low as

$1350.68 \pm 0.147 \mathrm{SE}$ (standard error) per year (Marshall, Dudgeon \& Bennett, 2011b) (Table 1). In

136 the present study, we used the life history data of these two populations to serve as reference

137 points for our demographic analyses.

138

139 Population model

140 The population model was based on a three-stage life cycle (Fig. 1). The addition of further life

141 stages may have increased model accuracy, but these are the only currently distinguishable 
142 stages in $M$. alfredi. The rate at which individuals survive and remain in the same life stage (as

143 opposed to growing into the next life stage) equals $P_{i}$, where $i$ indicates Y (yearling), J (juvenile)

144 or A (adult), and was calculated following Caswell (2001):

145

$146 P_{i}=\sigma_{i}\left(1-\gamma_{i}\right)$

(Equation 1)

147

148 where $\sigma_{l}(i=\mathrm{Y}, \mathrm{J}, \mathrm{A})$ is the estimated survival rate for each life stage (Table 1). The parameter $\gamma_{i}$

149 is the transition rate from one life stage to the next (expressed per year); in this case, from

150 yearling to juvenile $\left(\gamma_{\mathrm{Y}}\right)$ or from juvenile to adult $\left(\gamma_{\mathrm{J}}\right)$. Each transition rate $\gamma_{\mathrm{i}}$ was calculated as $\gamma_{i}$

$151=1 / D_{i}$, where $D_{i}$ is the duration (in years) of either the yearling $(i=\mathrm{Y})$ or juvenile life stage $(i=$

$152 \mathrm{~J})($ Table 1). The rate (per year) at which individuals survive and grow into the next life stage is 153 defined as:

154

$155 G_{i}=\sigma_{i} \gamma_{i}$

(Equation 2)

156

157 where $i$ indicates $\mathrm{Y}$ (yearling) or $\mathrm{J}$ (juvenile). The number of offspring produced each year equals

$158 F_{\mathrm{A}}$. These equations result in the following population projection matrix, which has a projection 159 interval of one year:

160

$161 \quad \mathbf{A}=\left[\begin{array}{ccc}P_{\mathrm{Y}} & 0 & F_{\mathrm{A}} \\ G_{\mathrm{Y}} & P_{\mathrm{J}} & 0 \\ 0 & G_{\mathrm{J}} & P_{\mathrm{A}}\end{array}\right]$

(Equation 3)

162

163 Parameterisation and model performance 
164 Following Kashiwagi (2014), and as is common practice (Caswell [2001]), the population model

165 was parameterised for females under the assumption that their growth and survival rates are not

166 too dissimilar to those of male reef manta rays. We set the stage transition rates $\gamma_{i}$ in Equations 1

167 and 2 constant at $\gamma_{\mathrm{Y}}=1 / D_{\mathrm{Y}}=1 / 1=1$ and $\gamma_{\mathrm{J}}=1 / D_{\mathrm{J}}=1 / 8=0.125$ (Table 1 ), and assumed

168 that females produce one pup every two years, so that $F_{\mathrm{A}}=0.5$ per year. Because little is known

169 about yearling and juvenile survival rates (Marshall et al., 2011a; but see Kashiwagi, 2014), we

170 conducted each demographic analysis (explained in the next section) for all combinations of

171 values of yearling annual survival rate $\left(\sigma_{Y}\right)$ and juvenile annual survival rate $\left(\sigma_{J}\right)$ within the

172 interval $[0.5,1]$ in increments of 0.005 (Table 1). We conducted each analysis using the observed

173 adult annual survival rate of reef manta rays off the coast of Mozambique, which is $\sigma_{\mathrm{A}}=0.68$

174 (Marshall, Dudgeon \& Bennett, 2011b), a 20\%-reduced adult annual survival rate of $\sigma_{\mathrm{A}}=0.54$,

175 and 20\%- and 40\%-increased adult annual survival rates of $\sigma_{\mathrm{A}}=0.82$ and $\sigma_{\mathrm{A}}=0.95$, respectively

176 (Table 1). The final value of $\sigma_{\mathrm{A}}=0.95$ is equal to the observed non-yearling annual survival rate

177 of reef manta rays in a stable population off the coast of Japan (Kashiwagi, 2014) (Table 1). To

178 assess the performance of our population model, we compared our predictions of population

179 growth rate, lifetime reproductive success and cohort generation time with the empirical

180 observations.

181

182 Demographic analyses

183 Firstly, we calculated the population growth rate $\lambda$ from the dominant eigenvalue of matrix $\mathbf{A}$

184 (Equation 3) for each of the abovementioned combinations of yearling, juvenile and adult annual 185 survival rates. Secondly, for each of the survival rate combinations, we performed an elasticity 186 analysis to investigate how sensitive the population growth rate $\lambda$ is to perturbations of each of 
187 the different growth, survival and fertility rates in the population projection matrix A (Equation

188 3). To this end, we calculated the elasticity matrix $\mathbf{E}$, where each element on row $m$ and column $189 n$ of matrix $\mathbf{E}, e_{m n}$, represents the proportional contribution of each associated demographic rate $190 P_{i}, G_{i}$ and $F_{A}$ in the population projection matrix $\mathbf{A}$ (Equation 3) to the population growth rate $\lambda$.

191 The elasticities were calculated as follows (Caswell, 2001):

192

$193 e_{m n}=\frac{a_{m n}}{\lambda} \frac{\partial \lambda}{\partial a_{m n}}$ (Equation 4)

where $a_{m n}$ are the elements of $\mathbf{A}$. The second part of the equation describes the sensitivities of $\lambda$ 196 to changes in the elements $a_{m n}$ of $\mathbf{A}$ (Caswell, 2001). The elasticities sum to 1, and give the proportional contributions of the matrix elements to the population growth rate $\lambda$. Therefore, the higher an elasticity value is relative to other elasticity values, the greater is the effect of the associated demographic rate on the population growth rate. matrix $\mathbf{R}=\mathbf{F N}$. The matrix $\mathbf{F}$ is a fertility matrix that describes the production of new individuals:

204

$205 \quad \mathbf{F}=\left[\begin{array}{ccc}0 & 0 & F_{A} \\ 0 & 0 & 0 \\ 0 & 0 & 0\end{array}\right]$

\section{(Equation 5)}

207 The matrix $\mathbf{N}$ is calculated as $\mathbf{N}=(\mathbf{I}-\mathbf{U})^{-1}$, where $\mathbf{I}$ is the identity matrix and $\mathbf{U}$ the transient 208 matrix that describes the growth and survival rates of the different stages: 
$210 \quad \mathbf{U}=\left[\begin{array}{ccc}P_{Y} & 0 & 0 \\ G_{Y} & P_{J} & 0 \\ 0 & G_{J} & P_{A}\end{array}\right]$

(Equation 6)

211

212 Fourthly, for each combination of yearling, juvenile and adult annual survival rates, we

213 calculated cohort generation time as the mean age of offspring production in a cohort of

214 yearlings (Caswell, 2009):

215

$216 T_{c}=\operatorname{diag}\left(\mathbf{F N e}_{\mathbf{Y}}\right)^{-1} \mathbf{F N U N e}_{\mathbf{Y}}$,

(Equation 7)

217

218 where the vector $\mathbf{e}_{\mathbf{Y}}$ is a vector with 1 in the first entry (for yearlings) and zeros in the second and

219 third entries for juveniles and adults, respectively. Finally, we used the population growth rates

220 that were calculated at step one to project a population of 500 individuals forward over a period

221 of 10 years. All of the demographic analyses were conducted in MATLAB ${ }^{\circledR}$ R2014b

222 (MathWorks ${ }^{\circledR}$, MA, USA).

223

224

\section{RESULTS}

\section{Model performance}

226 Overall, the predictions from our PPM matched the empirical observations well. Firstly, the

227 predicted values for the population growth rate $\lambda$ ranged from 0.64 to 1.13 , depending on the

228 values of yearling, juvenile and adult survival rates (Fig. 2; Table 2). This range includes the

229 range of observed population growth rate values, but also slightly exceeds the range of observed

230 values (Table 2). Similarly, the range of predicted values of lifetime reproductive success $\mathrm{R}_{0}$ 
231 (0.06-6.20) (Fig. 3; Table 2) included the range of observed values of $\mathrm{R}_{0}$, but the highest

232 predicted value of $\mathrm{R}_{0}$ exceeded the highest observed value of $\mathrm{R}_{0}$ (Table 2 ). The predicted values

233 for cohort generation time were very low (Fig. 4; Table 2), and much lower than the observed

234 cohort generation times in most cases (Table 2). Only when adult annual survival rate was at its

235 highest $\left(\sigma_{\mathrm{A}}=0.95\right)$ (Fig. 4D) did the predicted cohort generation time match the observed value

236 (Table 2).

237

238 Summary of the demographic analyses

239 Because the results of our demographic analyses are complex, we first provide a summary to aid

240 in the interpretation of the specific results (below). Because little is known about survival rates of

241 yearling and juvenile reef manta rays, we explored the effects of a range of values of yearling

242 and juvenile annual survival rates on lifetime reproductive success, population growth rate and

243 cohort generation time. We also varied the adult annual survival rate from as low as 0.54 , which

244 is $20 \%$ lower than the observed annual survival rate of adults ( 0.68 per year) off the coast of

245 Mozambique (Marshall, Dudgeon \& Bennett, 2011b), to as high as 0.95 per year, which equals

246 the observed adult annual survival rate in the stable population off the coast of the Yaeyama

247 Islands (Kashiwagi, 2014). The effect of an increase in adult annual survival rate across this

248 range of values was straightforward: with increasing adult annual survival rate, the values of all

249 three population descriptors also increased. However, variation in yearling and juvenile annual

250 survival rates had different and varying effects on the population descriptors that we

251 investigated. In the case of population growth rate, changes in these two survival rates had

252 additive effects on the population growth rate, but interactive (multiplicative) effects on mean

253 lifetime reproductive success, whereas cohort generation time was unaffected by variation in the 
254 juvenile annual survival rate. In addition, the effect of an increase in juvenile annual survival rate

255 was always of a far greater magnitude on population growth rate, mean lifetime reproductive

256 success and cohort generation time than the effect that the same increase in yearling or adult

257 annual survival rate had on these population descriptors.

258

259 Specific results of the demographic analyses

260 Calculating the population growth rate $\lambda$ for all of the different values of yearling, juvenile and

261 adult annual survival rates revealed that for the observed adult annual survival rate of $\sigma_{\mathrm{A}}=0.68$

262 (Marshall, Dudgeon \& Bennett, 2011b), populations can only persist if both yearling and

263 juvenile annual survival rates are high $\left(\sigma_{\mathrm{Y}}>0.7\right.$ and $\left.\sigma_{\mathrm{J}}>0.95\right)$ (Fig. 2B; populations persist to

264 the right of the blue line, indicating population stability at $\lambda=1$ ). When applying the lower value

265 of adult annual survival rate $\left(\sigma_{\mathrm{A}}=0.54\right)$, populations can only persist if both yearling and

266 juvenile annual survival rates are almost at unity (Fig. 2A; populations persist to the right of the

267 blue line, indicating population stability at $\lambda=1)$. At higher values of $\sigma_{\mathrm{A}}\left(\sigma_{\mathrm{A}}=0.82\right.$ and $\sigma_{\mathrm{A}}=$

268 0.95), populations can persist at much lower values of yearling and juvenile annual survival rates

269 (Fig. 2C, D; populations persist to the right of the blue line, indicating population stability at $\lambda=$

270 1), e.g. if $\sigma_{\mathrm{A}}=0.95$, the yearling survival rate $\left(\sigma_{\mathrm{Y}}\right)$ can be as low as 0.5 , as long as the juvenile

271 survival rate is $\sigma_{\mathrm{J}}=0.8$ (Fig. 2D). Because the isoclines in each panel are neither horizontal nor

272 vertical, we can infer that for a constant value of $\sigma_{\mathrm{Y}}\left(\right.$ or $\left.\sigma_{\mathrm{J}}\right)$, the population growth rate depends

273 on what the value of $\sigma_{\mathrm{J}}\left(\right.$ or $\left.\sigma_{\mathrm{Y}}\right)$ is. However, because the isoclines in each plot are parallel, we

274 can infer that these effects are additive, and that therefore there is no interactive effect between

$275 \sigma_{\mathrm{Y}}$ and $\sigma_{\mathrm{J}}$ on $\lambda$ (i.e. the magnitude of an effect of $\sigma_{\mathrm{Y}}$ on $\lambda$ does not depend on the value of $\sigma_{\mathrm{J}}$, and

276 vice versa). 
278 the elasticity of the population growth rate $\lambda$ to each of the demographic rates of each life stage

279 in the PPM (Equation 3). This revealed that, depending on the survival rate values, $\lambda$ was either most sensitive to $P_{\mathrm{A}}$, the rate at which adults survive and remain in the adult stage, or $P_{\mathrm{J}}$, the rate

281 at which juveniles survive and remain in the juvenile life stage (Fig 2; white areas in each panel denote survival rate values where $\lambda$ is most sensitive to $P_{\mathrm{A}}$, and grey areas denote survival rate values for which $\lambda$ is most sensitive to $P_{\mathrm{J}}$ ). Interestingly, with increasing values of the adult annual survival rate $\sigma_{\mathrm{A}}$ (going from Fig. 2A to Fig. 2D), the region of yearling survival rate $\left(\sigma_{\mathrm{Y}}\right)$ values for which $\lambda$ is most sensitive to $P_{\mathrm{A}}$ (white areas) increases, whereas the region of yearling survival rate values for which $\lambda$ is most sensitive to $P_{\mathrm{J}}$ (grey areas) decreases. These shifts indicate that the elasticity results were independent of juvenile annual survival rate $\left(\sigma_{\mathrm{J}}\right)$; rather, whether or not $\lambda$ is most sensitive to perturbations in $P_{\mathrm{J}}$ or $P_{\mathrm{A}}$ critically depended on the values of $\sigma_{\mathrm{Y}}$ and $\sigma_{\mathrm{A}}$ (Fig. 2).

We then investigated the effect of variation in yearling, juvenile and adult survival rates on mean lifetime reproductive success. The results were qualitatively similar to those obtained for the population growth rate: with increasing values of the adult annual survival rate $\sigma_{\mathrm{A}}$, populations can persist at ever lower values of yearling and juvenile annual survival rates (Fig. 3; populations persist to the right of the blue line, indicating population stability at $R_{0}=1$ ). In contrast to the results for population growth rate, however, the isoclines in each panel are not parallel and are unevenly spaced (Fig. 3), indicating that the yearling and juvenile annual survival rates $\sigma_{\mathrm{Y}}$ and $\sigma_{\mathrm{J}}$ have an interactive effect on lifetime reproductive success, i.e. the magnitude of an effect of $\sigma_{\mathrm{Y}}$ on lifetime reproductive success depends on the value of $\sigma_{\mathrm{J}}$, and vice versa. The uneven spacing of the isoclines for each value of adult annual survival rate (Fig. 
3003 ) indicates that, with increasing values of yearling and juvenile annual survival rates, lifetime

301 reproductive success increases at an ever higher rate. This increase in lifetime reproductive

302 success is greater with increasing values of yearling or adult annual survival rates than with

303 increasing values of juvenile annual survival rates.

304 Regarding cohort generation time, for each value of adult annual survival rate $\left(\sigma_{\mathrm{A}}\right)$,

305 cohort generation time increases at an accelerating rate with increasing values of yearling annual

306 survival rate $\left(\sigma_{Y}\right)$; hence, a slight increase in a high value of $\sigma_{Y}$ results in a far larger increase in

307 cohort generation time than a slight increase in a low value of $\sigma_{Y}$. However, there is no effect of

308 juvenile annual survival rate $\left(\sigma_{\mathrm{J}}\right)$, because the increase in cohort generation time with increasing

309 values of $\sigma_{Y}$ is the same for each value of $\sigma_{\mathrm{J}}$ (Fig. 4). Cohort generation time also increases at an

310 accelerating rate with increasing values of adult annual survival rate $\left(\sigma_{\mathrm{A}}\right)$; consequently, a slight

311 increase in a high value of $\sigma_{\mathrm{A}}$ results in a far larger increase in cohort generation time than a

312 slight increase in a low value of $\sigma_{\mathrm{A}}$ (Fig. 4).

Finally, we used the predicted population growth rates (Fig. 2) to project a starting

314 population of 500 individuals forward over 10 years to investigate the population consequences

315 of variation in yearling, juvenile and adult survival rates. The combinations of yearling, juvenile

316 and adult survival rate values at which populations are stable and the projected population size

317 remains at 500 individuals after 10 years (indicated by the green lines in Fig. 5) were the same as

318 those obtained from the population growth rate (Fig. 2) and lifetime reproductive success (Fig. 3)

319 analyses. In each panel in Fig. 5, combinations of survival rate values to the right of the green

320 line correspond to population increases. Comparing the different panels shows that the increase

321 in population size is greater at higher values of the adult annual survival rate $\left(\sigma_{\mathrm{A}}\right)(\mathrm{Fig} .5)$. The

322 lowest observed population size of reef manta rays off the coast of Mozambique is 149 
323 individuals (Marshall, Dudgeon \& Bennett, 2011b), and is indicated by red lines in Fig. 5.

324 Matching this lowest observed population size to our population projections reveals that it

325 corresponds to ever lower values of yearling annual survival rate $\left(\sigma_{Y}\right)$ and juvenile annual

326 survival rate $\left(\sigma_{\mathrm{J}}\right)$ as the adult annual survival rate $\left(\sigma_{\mathrm{A}}\right)$ increases in value. This suggests that the

327 decrease in population size over 10 years is less at higher values of the adult annual survival rate

328 than at lower values.

\section{DISCUSSION}

\section{Model performance}

In this study, we developed a population model for reef manta rays that we used to conduct a detailed analysis of reef manta ray demography. With this analysis, we aim to increase our understanding of the drivers of population change in reef manta rays, and how perturbations to demographic rates, such as a decrease in survival due to targeted fishing and by-catch, affect their population fluctuations. Before we discuss our findings against current understanding of reef manta ray demography, however, it is necessary: (i) to know how well our PPM performed

339 in describing the general characteristics of reef manta ray populations, and (ii) to check the soundness of the life history data that we used to parameterised the PPM. The data that we used

341 to model growth and reproduction are sound, as several studies on the growth and reproduction 342 of reef manta rays report very similar results (Marshall \& Bennet, 2010; Marshall, Dudgeon \&

343 Bennett, 2011b; Kashiwagi, 2014). Less is known about individual survival in this species.

344 Marshall, Dudgeon \& Bennett (2011b) studied adult survival in a reef manta ray population off

345 the southern coast of Mozambique and estimated adult survival rate at $0.68( \pm 0.15 \mathrm{SE})$ per year. 
346 With our own preliminary, capture-mark-recapture analysis of sight-re-sight data of adult reef

347 manta rays off the southern coast of Mozambique (200 km south of the study site of Marshall,

348 Dudgeon \& Bennett [2011b]) we obtained an adult survival rate of $0.67( \pm 0.16 \mathrm{SE})$ per year

349 (I.B.C. van der Ouderaa \& Y. Tibiriçá, unpublished data). From the fact that each adult survival

350 rate estimate is within one standard error of the mean of the other estimate we infer that these

351 two estimates are not significantly different (Montgomery, 2012). The survival of yearling and

352 juvenile reef manta rays has been less studied, as individuals at these life stages do not frequently

353 visit the aggregation sites where demographic data on adults are typically collected (Marshall,

354 Dudgeon \& Bennett, 2011b). For this reason, we used a range of annual survival rate values for

355 yearlings and juveniles.

356 Overall, we found that the performance of our model was satisfactory; mean lifetime

357 reproductive success and population growth rates observed in different reef manta ray

358 populations were all within the ranges that we predicted from our population model. However,

359 the predicted population growth rate and lifetime reproductive success values sometimes

360 exceeded the observed values; this was probably due to the fact that we also investigated the

361 population consequences of annual survival rates of yearlings, juveniles and adults that were

362 lower and higher than the observed survival rates. For the reef manta ray population off the coast

363 of the Yaeyama Islands, the annual survival rates of all three life stages, as well as the population

364 growth rate, have been estimated: the yearling annual survival rate is estimated to be 0.63 and

365 juvenile and adult annual survival rates are both estimated as 0.95 (Kashiwagi, 2014). The

366 population growth rate associated with these values as predicted by our population model was

$367 \sim 1.01$ (Fig. 2D; $\sigma_{\mathrm{Y}}=0.63, \sigma_{\mathrm{J}}=\sigma_{\mathrm{A}}=0.95$ ), which is very close to the estimated population

368 growth rate of the Yaeyama Islands reef manta ray population of 1.02 per year (Kashiwagi, 
369 2014). The only discrepancy between the predicted and observed values was cohort generation

370 time at the lower adult annual survival rates of $0.54 \leq \sigma_{\mathrm{A}} \leq 0.82$ (Fig. $4 \mathrm{~A}-\mathrm{C}$ ). At these low

371 survival rates, adults do not live very long, which lowers the average age at which adults

372 reproduce and results in a low cohort generation time. Cohort generation time values have

373 probably been obtained from stable populations (Marshall et al., 2011a; Ward-Paige, Davis \&

374 Worm, 2013), in which annual adult survival rates are much higher. Indeed, at $\sigma_{\mathrm{Y}}=\sigma_{\mathrm{A}}=0.95$

375 (as found for the stable reef manta ray population off the coast of the Yaeyama Islands

376 [Kashiwagi, 2014]), the predicted cohort generation time was 18.5 years, which is very close to

377 the observed generation time of 19.4 years (Ward-Paige, Davis \& Worm, 2013). Overall, it is

378 rewarding that predictions from our population model match observations on the key population

379 descriptors of lifetime reproductive success, population growth rate and cohort generation time.

\section{Demographic analyses}

382 The demographic analysis revealed that the effects of variation in yearling and juvenile survival rates on population growth rate, mean lifetime reproductive success and cohort generation time are not straightforward, but some general patterns did emerge. Firstly, an increase in yearling or adult annual survival rate always elicited a greater response in population growth rate, mean lifetime reproductive success and cohort generation time than the same increase in juvenile annual survival rate. This suggests that a perturbation in yearling or adult annual survival rate will have far greater consequences for reef manta ray population dynamics than the same magnitude of perturbation in juvenile annual survival rate. Secondly, increases in any of the three population descriptors with increasing yearling or adult survival rate values was either linear, in

391 the case of population growth rate, or was at an accelerating rate, in the case of mean lifetime 
392 reproductive success and cohort generation time. The accelerating rates of increase are of

393 particular interest, because if yearling or adult annual survival rates are already high, a slight

394 increase can increase mean lifetime reproductive success by almost one pup (Fig. 3D), and

395 cohort generation time by a year to several years (Fig. 4D). Both of these effects can

396 significantly affect population structure and fluctuations. Therefore, in order to obtain an

397 accurate insight into reef manta ray population dynamics, accurate estimates of yearling and

398 juvenile survival rates should be obtained from natural populations.

399 One way of gaining a general insight into the population consequences of differences in

400 demographic rates is by using population models to project a population forward in time and

401 investigate its future size relative to its original size, which we did for a period of 10 years for all

402 combinations of yearling, juvenile and adult annual survival rates. The reef manta ray population

403 off the coast of Mozambique decreased by $88 \%$ between 2005 and 2011 due to variation in the

404 local environment, anthropogenic pressures and large-scale oceanographic influences (Rohner et

405 al., 2013). Our population projections confirm that the low observed adult annual survival rate of

406 adult reef manta rays off the coast of Mozambique of 0.68 per year (Marshall, Dudgeon \&

407 Bennett, 2011b) nearly always results in population decline, unless yearling and juvenile annual

408 survival rates are close to unity. However, because reef manta ray by-catch has recently

409 significantly increased in this region (Marshall, Dudgeon \& Bennett, 2011b; Pereira et al., 2014),

410 it is unlikely that the juvenile survival rate is close to unity. In the stable reef manta ray

411 population off the coast of the Yaeyama Islands, the yearling annual survival rate has been

412 estimated to be as low as 0.63 , probably because of predation (Kashiwagi, 2014). If we assume

413 that this yearling annual survival rate also applies to the Mozambique population, the

414 Mozambique population is predicted to continue to decrease in size, even if the juvenile annual 
415 survival rate is at unity (Fig. 5B). Therefore, unless the survival rates of reef manta rays in

416 populations off the coast of Mozambique increase (by reducing direct fishing and by-catch), it is

417 unlikely that this population will stop declining.

418

\section{Conservation implications}

420 Many manta ray populations across the globe are declining, according to the IUCN Red List for 421 Threatened Species (Marshall et al., 2011a; but see Kashiwagi [2014] for an exception). One

422 way of increasing our understanding of how such declines can be reduced or even halted is by

423 conducting elasticity analyses of a demographic model. The results of such analyses identify

424 which demographic rates of which life stages have the greatest effect on population growth. By

425 targeting conservation research and management on those rates and life stages, vulnerable

426 populations can be protected from further decline (Benton \& Grant, 1999; Carslake, Townley \&

427 Hodgson, 2009). Our elasticity analysis revealed that the population growth rate is most sensitive

428 to change in either the adult survival rate or the rate at which juveniles survive but stay in the

429 juvenile stage (i.e. do not mature into adults). To exemplify how the results of this analysis can

430 be used, we compared the values predicted by our analysis to the values obtained in two reef

431 manta ray populations off the coasts of Mozambique and the Yaeyama Islands. In the case of

432 Mozambique, the observed adult annual survival rate is 0.68 (Marshall, Dudgeon \& Bennett,

433 2011b), and the observed population growth rate is estimated as 0.77 per year (Rohner et al.,

434 2013); according to our elasticity analysis (Fig. 2B), at these values, the population growth rate

435 will be most sensitive to changes in the adult annual survival rate. To prevent this population

436 declining further, the adult survival rate should be increased by reducing targeted and by-catch

437 fishing through the protection of aggregation sites that are often frequented by adults. Our 
438 analyses indicate that if the adult survival rate increases to 0.95 per year, then the population

439 growth rate is close to unity and the Mozambique reef manta ray population would be stable.

440 Regarding the stable population off the coast of the Yaeyama Islands, the adult annual survival

441 rate is 0.95 , and according to our elasticity analysis, this population will also be most sensitive to

442 changes in the adult annual survival rate. Although this population is not currently subject to

443 direct fishing pressure (Kashiwagi, 2014), our results predict that any changes in adult survival

444 will greatly affect it.

445 A previous demographic analysis that was based on a generic reef manta ray life cycle

446 and not on a specific manta ray population found that the intrinsic population growth rate $r$ was

447 most sensitive to changes in the offspring production rate and not the mortality rate (Dulvy et al.,

448 2014). However, unlike our elasticity analysis, Dulvy et al.'s (2014) sensitivity analysis

449 investigated how additive perturbations in life history parameters affect the intrinsic population

450 growth rate, whereas we investigated how proportional perturbations in demographic rates affect

451 the long-term population growth rate. We used the second part of Equation 4 to run a sensitivity

452 analysis in order to investigate how additive perturbations affect the population growth rate, and

453 found that the population growth rate is most sensitive to perturbations in $G_{\mathrm{J}}$ or $P_{\mathrm{A}}$, depending on

454 the values of yearling, juvenile and adult annual survival rates (Appendix: Fig. A1). However,

455 these results are not very informative, because the demographic rates in our population model are

456 measured in different units; survival rates are probabilities, and only have values of between zero

457 and unity, whereas reproduction rate has no such restrictions. Therefore, it is difficult to compare

458 the sensitivity of the population growth rate to changes in survival and growth rates with the

459 sensitivity of the reproductive rate. Therefore, we focus on the results of the elasticity analysis,

460 which suggest that reef manta ray populations off the coast of Mozambique and Japan are most 
461 sensitive to perturbations in the adult annual survival rate. The demographic rates that comprise

462 our population matrix are determined by the underlying parameters $\sigma_{\mathrm{i}}$ (survival rate) and $\gamma_{\mathrm{i}}$

463 (stage-specific transition rate); however, because the adult annual survival rate $P_{\mathrm{A}}$ equals $\sigma_{\mathrm{A}}$ and

464 is independent of $\gamma_{i}$, the population growth rate is indeed most sensitive to perturbations in adult

465 survival at high adult survival rates, which is typical for long-lived animals (Brault \& Caswell,

466 1993; Caswell, 2001). This indicates that effective management and legislation is urgently

467 needed to avoid the local extinction of the reef manta ray population off the coast of

468 Mozambique. The following two approaches should be taken: (1) the species should be protected

469 against fishing, including accidental catch; and (2) aggregation areas should be protected. The

470 behaviour of reef manta rays at cleaning stations makes targeted fishing a potential threat, but

471 also creates an opportunity for site-specific protection. By protecting aggregation sites, adults,

472 which are regular visitors to such sites (Marshall, Dudgeon \& Bennett, 2011b; Kashiwagi, 2014),

473 should exhibit increased survival rates, which will result in an increase in the population growth

474 rate.

475

476 Alternative approaches and considerations

477 One aspect that we have not yet touched upon is variability in demographic rates. Such

478 variability can, for example, occur over time through changes in environmental conditions.

479 Exploring the population consequences of such temporal stochasticity requires in depth

480 knowledge on how different environmental conditions affect demographic rates, of which we

481 currently know very little. Variability in demographic rates can also manifest itself through the

482 accuracy with which demographic rates are estimated. Such information is only available for

483 adult annual survival rate in the Mozambique population (estimated at $\sigma_{\mathrm{A}}=0.68 \mathrm{yr}^{-1} \pm 0.15 \mathrm{SE}$ ) 
484 (Marshall, Dudgeon \& Bennett, 2011b), and for non-yearling annual survival rate in the Japan 485 population (0.95, with a 95\% confidence interval of $0.94-0.96)$ (Kashiwagi, 2014). In the latter

486

487

488

489

490

491

492

493

494

495

496

497

498

499

500

501

502

503

504

505

case, the accuracy of the estimated adult survival rate is very high and predictions on population dynamics as presented in panels (D) of Figs. $2-4$ will vary little within the $95 \%$ confidence interval. In contrast, the accuracy of the estimated adult annual survival rate in the Mozambique population is much lower, but we can use our results to assess potential effects of this variability by exploring model output within one standard error range from the mean. That is, subtracting one standard error from the mean adult annual survival rate results in $\sigma_{\mathrm{A}}=0.68-0.15=0.53$; model output in that case will be almost equal to the results presented in panels (A) of Fig. $2-4$ where $\sigma_{\mathrm{A}}=0.54$. Adding one standard error to the mean adult survival rate results in $\sigma_{\mathrm{A}}=0.68$ $+0.15=0.83$; model output in that case will be almost equal to the results presented in panels (C) of Fig. $2-4$ where $\sigma_{A}=0.82$. This comparison informs on the range of values of $\lambda, R_{0}$ and generation time that can be expected when we take the (in)accuracy of the estimated adult annual survival rate into account. One important issue is the fact that the elasticity results differ within the range $0.54 \leq \sigma_{\mathrm{A}} \leq 0.82$ at intermediate values of yearling annual survival rate, $\sigma_{\mathrm{Y}}$. Specifically, within the range $0.6 \leq \sigma_{\mathrm{Y}} \leq 0.9$, depending on the value of $\sigma_{\mathrm{A}}$, the population growth rate is either most sensitive to $P_{\mathrm{A}}$, the rate at which adults survive and remain in the adult stage, or $P_{\mathrm{J}}$, the rate at which juveniles survive and remain in the juvenile life stage (Fig. 2). However, if we take the estimate for yearling annual survival rate of $\sigma_{Y}=0.63$ (Kashiwagi, 2014) and assume that $\sigma_{\mathrm{A}}>>0.54$, the population growth rate is always most sensitive to perturbation of $\mathrm{P}_{\mathrm{A}}$ and our conclusions presented above on reef manta ray conservation are unaffected. 
Finally, it is important to realise that different techniques exist that relate the dynamics of

507 populations to the demographic rates of individuals, and include physiologically structured

508 population models (Metz \& Diekmann, 1986), delay-differential equation models (Nisbet \&

509 Gurney, 2003), individual-based models (Grimm \& Railsback, 2005), integral projection models

510 (IPMs) (Easterling, Ellner \& Dixon, 2000), and PPMs (Caswell, 2001). These methodologies all

511 link individual state to population structure, but differ in their mathematical approaches.

512 Structured population models such as PPMs and IPMs are particularly useful for investigating

513 how demographic changes affect population dynamics. They are closely and easily linked to

514 field and experimental data, and require relatively straightforward mathematical techniques from

515 matrix calculus (Coulson, 2012). IPMs have the added benefit that they can be used to

516 investigate simultaneous ecological and rapid evolutionary change in quantitative characters, life

517 history evolution and population dynamics (Smallegange \& Coulson, 2013). However, IPMs are

518 data hungry, because their parameterisation requires extensive, long-term datasets on the life

519 history trajectories of individuals (Coulson, 2012). Because these data are currently not available

520 for reef manta rays, we developed a PPM that included the three life stages that can currently be

521 distinguished in reef manta rays: yearlings, juveniles and adults (Marshall et al., 2011a). Future

522 studies should, however, aim to develop a reef manta ray IPM that can take any evolutionary

523 responses in life history parameters to environmental change into consideration.

525 ACKNOWLEDGEMENTS

526 We thank Hal Caswell for providing feedback on an earlier draft and Spiral Scientific Editing

527 Services for editorial assistance. 
529

530

531

532

533

534

535

536

537

538

539

540

541

542

543

544

545

546

547

548

549

550

\section{REFERENCES}

Benton TG, Grant A. 1999. Elasticity analysis as an important tool in evolutionary and population ecology. Trends in Ecology and Evolution 14:467-471.

Berkes F, Hughes TP, Steneck RS, Wilson JA, Bellwood DR, Crona B, Folke C, Gunderson LH, Leslie HM, Norberg J, Nyström M, Olsson P, Österblom H, Scheffer M, Worm B. 2006. Globalization, roving bandits, and marine resources. Science 311:1557-1558 DOI 10.1126/science.1122804.

Brault S, Caswell H. 1993. Pod-specific demography of killer whales (Orcinus orca). Ecology 74:1444-1454.

Carslake D, Townley S, Hodgson DJ. 2009. Patterns and rules for sensitivity and elasticity in population projection matrices. Ecology 90:3258-3267.

Caswell H. 2001. Matrix population models. Sunderland: Sinauer Associates.

Caswell H. 2009. Stage, age and individual stochasticity in demography. Oikos 118:1763-1782.

Clarke SC. 2004. Understanding pressures on fishery resources through trade statistics: a pilot study of four products in the Chinese dried seafood market. Fish and Fisheries 5:53-74 DOI 10.1111/j.1467-2960.2004.00137.x.

Clarke SC, McAllister MK, Milner-Gulland EJ, Kirkwood GP, Michielsens CGJ, Agnew DJ, Pikitch EK, Nakano H, Shivji MS. 2006. Global estimates of shark catches using trade records from commercial markets. Ecology Letters 9:1115-1126 DOI 10.1111/j.14610248.2006.00968.x.

Coulson T. 2012. Integral projection models, their construction and use in posing hypotheses in ecology. Oikos 121:1337-1350. 
551 Couturier LIE, Dudgeon CL, Pollock KH, Jaine FRA, Bennett MB, Townsend KA, Weeks

552 SJ, Richardson AJ. 2014. Population dynamics of the reef manta ray Manta alfredi in

553

554

555

556 eastern Australia. Coral Reefs 33:329-342 DOI: 10.1007/s00338-014-1126-5.

Couturier LIE, Marshall AD, Jaine FRA, Kashiwagi T, Pierce SJ, Townsend KA, Weeks

SJ, Bennett MD, Richardson AJ. 2012. Biology, ecology and conservation of the

557 Mobulidae. Journal of Fish Ecology 80:1075-1119.

Dulvy NK, Baum JK, Clarke S, Compagno LJV, Cortés E, Domingo A, Fordham S, Fowler

558 S, Francis MP, Gibson C, Martínez J, Musick JA, Soldo A, Stevens JD, Valenti S. 2008. You can swim but you can't hide: the global status and conservation of oceanic pelagic sharks and rays. Aquatic Conservation: Marine and Freshwater Ecosystems 18:459-482.

Dulvy NK, Pardo SA, Simpfendorfer CA, Carlson JK. 2014. Diagnosing the dangerous demography of manta rays using life history theory. PeerJ 2:e400; DOI 10.7717/peerj.400

Easterling MR, Ellner SP, Dixon PM. 2000. Size-specific sensitivity: applying a new structured population model. Ecology 81:694-708.

Grimm V, Railsback, SF. 2005. Individual-based modeling and ecology. Princeton: Princeton University Press.

Lenzen M, Moran D, Kanemoto K, Foran B, Lobefaro L, Geschke A. 2012. International

572 trade drives biodiversity threats in developing nations. Nature 486:109-112 DOI 10.1038/nature11145. 
574 Marshall AD, Bennett MB. 2010. Reproductive ecology of the reef manta ray Manta alfredi in

575 southern Mozambique. Journal of Fish Biology 77:169-190.

576 Marshall AD, Kashiwagi T, Bennett MB, Deakos M, Stevens G, McGregor F, Clark T,

577 Ishihara H, Sato K. 2011a. Manta alfredi. The IUCN Red List of Threatened Species

$578 \quad$ Version 2015.2.

579 Marshall AD, Dudgeon CL, Bennett MB. 2011b. Size and structure of a photographically 580 identified population of manta rays Manta alfredi in southern Mozambique. Marine Biology $581 \quad$ 158:1111-1124.

582

583

584

585

586

587

588

589

590

591

592

593

594

595

596

Metz JAJ, Diekmann O. 1986. The dynamics of physiologically structured populations. Berlin: Springer.

Montgomery DC. 2012. Design and analysis of experiments. John Wiley \& Sons.

Nisbet RM, Gurney WSC. 2003. Modelling fluctuating populations. New Jersey: Blackburn Press.

Pereira MAM, Litulo C, Santos R, Leal M, Fernandes RS, Tibiriçá Y, Williams J, Atanassov B, Carreira F, Massingue A, Marques da Silva I. 2014. Mozambique marine ecosystems review. Maputo: Biodinâmica/CTV, 139.

Rohner CA, Pierce SJ, Marshall AD, Weeks SJ, Bennett MB, Richardson AJ. 2013. Trends in sightings and environmental influences on a coastal aggregation of manta rays and whale sharks. Marine Ecology Progress Series 482:153-168.

Sadovy Y, Cheung WL. 2003. Near extinction of a highly fecund fish: the one that nearly got away. Fish and Fisheries 4:86-99 DOI 10.1046/j.1467-2979.2003.00104.x.

Smallegange IM, Coulson T. 2013. Towards a general, population-level understanding of ecoevolutionary change. Trends in Ecology and Evolution 28:143-148. 
597 Tibiriçá Y, Birtles A, Valentine P, Miller DK. 2011. Diving tourism in Mozambique: an $598 \quad$ opportunity at risk? Tourism in Marine Environments 7:141-151.

599 Ward-Paige CA, Davis B, Worm B. 2013. Global population trends and human use patterns of $600 \quad$ Manta and Mobula rays. PLoS ONE 8:e74835 DOI: 10.1371/journal.pone.0074835.

601 White WT, Giles J, Dharmadi D, Potter IC. 2006. Data on the bycatch fishery and 602 reproductive biology of mobulid rays (Myliobatiformes) in Indonesia. Fisheries Research 603 82:65-73. 
Table 1. Life history data of different reef manta ray populations. Shown are annual survival rates, $\sigma_{i}$, duration of different life stages, $D_{i}$, where $i=\mathrm{Y}$ (yearlings), $i=\mathrm{J}$ (juveniles) and $i=\mathrm{A}$ (adults), and fertility rate of adults, $F_{\mathrm{A}}$. Indicated are values estimated from data collected from populations off the coast of southern Mozambique and off the coast of Yaeyama Islands, Japan. Also shown are the values that were used in our demographic analyses.

\begin{tabular}{|c|c|c|c|c|c|}
\hline & Explanation & $\begin{array}{l}\text { Value in } \\
\text { analyses }\end{array}$ & $\begin{array}{l}\text { Observed } \\
\text { value }\end{array}$ & $\begin{array}{l}\text { Location of } \\
\text { observation }\end{array}$ & $\begin{array}{l}\text { Reference for } \\
\text { observed value }\end{array}$ \\
\hline$\sigma_{Y}$ & $\begin{array}{l}\text { Annual survival rate of } \\
\text { yearlings }\end{array}$ & $0.5-1.0$ & 0.63 & Japan & Kashiwagi, 2014 \\
\hline$\sigma_{\mathrm{J}}$ & $\begin{array}{l}\text { Annual survival rate of } \\
\text { juveniles }\end{array}$ & $0.5-1.0$ & 0.95 & Japan & Kashiwagi, 2014 \\
\hline$\sigma_{\mathrm{A}}$ & Annual survival rate of adults & $\begin{array}{l}\{0.54,0.68 \\
0.82,0.95\}\end{array}$ & 0.68 & Mozambique & $\begin{array}{r}\text { Marshall, Dudgeon, \& } \\
\text { Bennett, 2011b }\end{array}$ \\
\hline & & & 0.95 & Japan & Kashiwagi, 2014 \\
\hline$D_{\mathrm{Y}}$ & $\begin{array}{l}\text { Duration of yearling stage } \\
\text { (years) }\end{array}$ & 1 & 1 & $\begin{array}{r}\text { not specified/ } \\
\text { Japan }\end{array}$ & $\begin{array}{r}\text { Marshall et al., 2011a; } \\
\text { Kashiwagi, } 2014\end{array}$ \\
\hline$D_{\mathrm{J}}$ & $\begin{array}{l}\text { Average duration of (female) } \\
\text { juvenile stage (years) }\end{array}$ & 9 & $8-10$ & $\begin{array}{r}\text { not specified/ } \\
\text { Japan }\end{array}$ & $\begin{array}{r}\text { Marshall et al., 2011a; } \\
\text { Kashiwagi, } 2014\end{array}$ \\
\hline$D_{\mathrm{A}}$ & $\begin{array}{l}\text { Duration of adult stage } \\
\text { (years) }\end{array}$ & 31 & 31 & $\begin{array}{r}\text { not specified/ } \\
\text { Japan }\end{array}$ & $\begin{array}{r}\text { Marshall et al., 2011a; } \\
\text { Kashiwagi, } 2014\end{array}$ \\
\hline$F_{\mathrm{A}}$ & $\begin{array}{l}\text { Average number of pups per } \\
\text { year }\end{array}$ & 0.5 & 0.5 & Mozambique & $\begin{array}{r}\text { Marshall \& Bennett } \\
2010\end{array}$ \\
\hline
\end{tabular}


Table 2. Predicted and observed population descriptors for different reef manta ray populations. The population descriptors are: population growth rate $(\lambda$, expressed per year), mean lifetime reproductive success $\left(R_{0}\right)$, and cohort generation time $\left(T_{c}\right.$, years). Predicted values given are the minimum and maximum values from our demographic analyses (Fig. 2-4); observed values are taken from different locations around the world (locations are indicated).

\begin{tabular}{|c|c|c|c|c|c|}
\hline & $\begin{array}{l}\text { Predicted } \\
\text { range }\end{array}$ & $\begin{array}{l}\text { Observed } \\
\text { value }\end{array}$ & Explanation of observed value & $\begin{array}{l}\text { Location of } \\
\text { observation }\end{array}$ & $\begin{array}{l}\text { Reference for } \\
\text { observed value }\end{array}$ \\
\hline \multirow[t]{3}{*}{$\lambda$} & $0.64-1.13$ & 0.77 & $\begin{array}{l}\text { Calculated from the observation } \\
\text { of } 88 \% \text { decline between } 2005- \\
2011\end{array}$ & Mozambique & Rohner et al., 2013 \\
\hline & & 0.98 & $\begin{array}{l}\text { Calculated from the observation } \\
\text { of } 80 \% \text { decline over } 75 \text { years }\end{array}$ & not specified & Marshall et al., 2011a \\
\hline & & 1.02 & $\begin{array}{l}\text { Estimated using POPAN models } \\
\text { covering } 1987-2009\end{array}$ & Japan & Kashiwagi, 2014 \\
\hline \multirow[t]{2}{*}{$R_{0}{ }^{(1)}$} & $0.06-6.20$ & 0.60 & $\begin{array}{l}\text { Calculated using IUCN data } \\
\text { (Marshall et al. 2011a) }^{(1)} \text { : } \\
T_{c}=25 \text { and } \lambda=0.98\end{array}$ & not specified & Marshall et al., 2011a \\
\hline & & 0.02 & $\begin{array}{l}\text { Worst-case scenario calculated } \\
\text { using slowest life history } \\
\text { values }^{(1)}: T_{c}=19.4 \text { and } \lambda=0.77\end{array}$ & not specified & $\begin{array}{r}\text { Marshall et al., 2011a; } \\
\text { Rohner et al., } 2013\end{array}$ \\
\hline \multirow[t]{2}{*}{$T_{c}$} & $3.89-20.40$ & 19.4 & $\begin{array}{l}\text { Mean of minimum ( } 6.75 \text { years }) \\
\text { and maximum ( } 32 \text { years) age of } \\
\text { adults }\end{array}$ & $\begin{array}{r}\text { Tropical Eastern } \\
\text { Pacific \& } \\
\text { Atlantic; Hawaii }\end{array}$ & $\begin{array}{r}\text { Ward-Paige, Ward- } \\
\text { Paige, Davis \& Worm, } \\
2013\end{array}$ \\
\hline & & 25 & $\begin{array}{l}\text { Mean of minimum (10 years) } \\
\text { and maximum ( } 40 \text { years) age of } \\
\text { adults }\end{array}$ & not specified & Marshall et al., 2011a \\
\hline
\end{tabular}

(1) $\mathrm{R}_{0}$ was calculated by taking the exponent of $T_{c} \times \log (\lambda)$ (Caswell 2001)

605 
606

$F_{A}$ (Fertility rate)

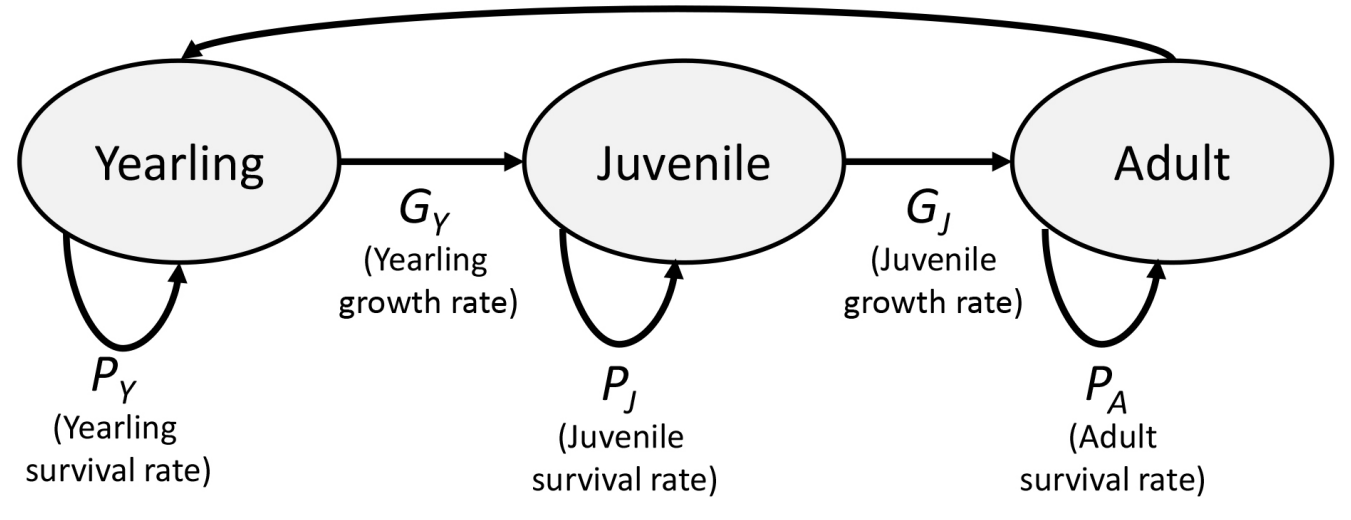

608

Figure 1 Life cycle of Manta alfredi. We distinguished three life stages: yearlings (Y), juveniles

609

(J) and adults (A). The rate at which individuals survive and remain in the same life stage equals

$P_{i}$, where $i$ indicates $\mathrm{Y}$ (yearling), $\mathrm{J}$ (juvenile) or A (adult); the rate at which individuals survive

611 and grow to the next life stage equals $G_{i}$, where $i$ indicates Y (yearling) or J (juvenile); the rate at

612 which adults produce yearlings equals $F_{A}$. See also Equations 1-3. 


\section{Population growth rate $(\lambda)$}

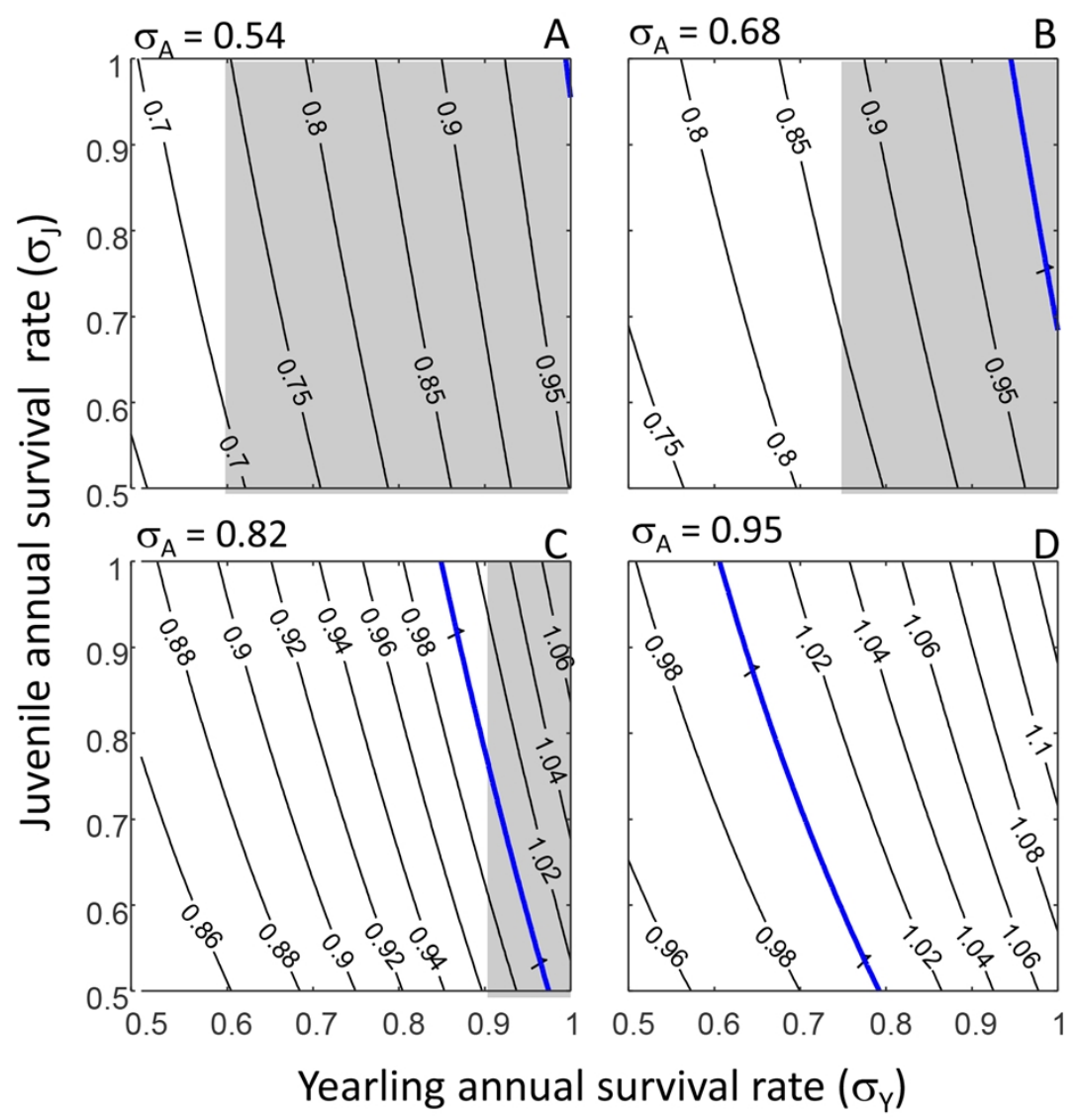

613

614 Figure 2 Population growth rate and elasticity results. Predicted population growth rate $\lambda$ in

615 relation to yearling annual survival rate $\left(\sigma_{\mathrm{Y}}\right)$ and juvenile annual survival rate $\left(\sigma_{\mathrm{J}}\right)$ shown for 616 each of four values of adult annual survival rate $\left(\sigma_{\mathrm{A}}\right): \sigma_{\mathrm{A}}=0.54(80 \%$ of observed rate $)(\mathrm{A}) ; \sigma_{\mathrm{A}}$

$617=0.68($ observed rate $)(\mathrm{B}) ; \sigma_{\mathrm{A}}=0.82(120 \%$ of observed rate $)(\mathrm{C})$; and $\sigma_{\mathrm{A}}=0.95(140 \%$ of

618 observed rate) (D). In each panel, isoclines denote equal values of the population growth rate $\lambda$.

619 The blue line in each panel denotes population stability at $\lambda=1$; values higher than $\lambda=1$ denote

620 increasing populations and value lower than $\lambda=1$ denote declining populations. The grey and

621 white areas in panels denote the elasticity results: white areas (panel D is all white) denote

622 parameter combinations where the population growth rate is most sensitive to $P_{\mathrm{A}}$, the rate at 
623 which adults survive and remain in the adult stage (Equation 3); grey areas denote parameter

624 combinations where the population growth rate is most sensitive to $P_{\mathrm{J}}$, the rate at which juveniles 625 survive and remain in the juvenile life stage (Equation 3). 


\section{Lifetime reproductive success}

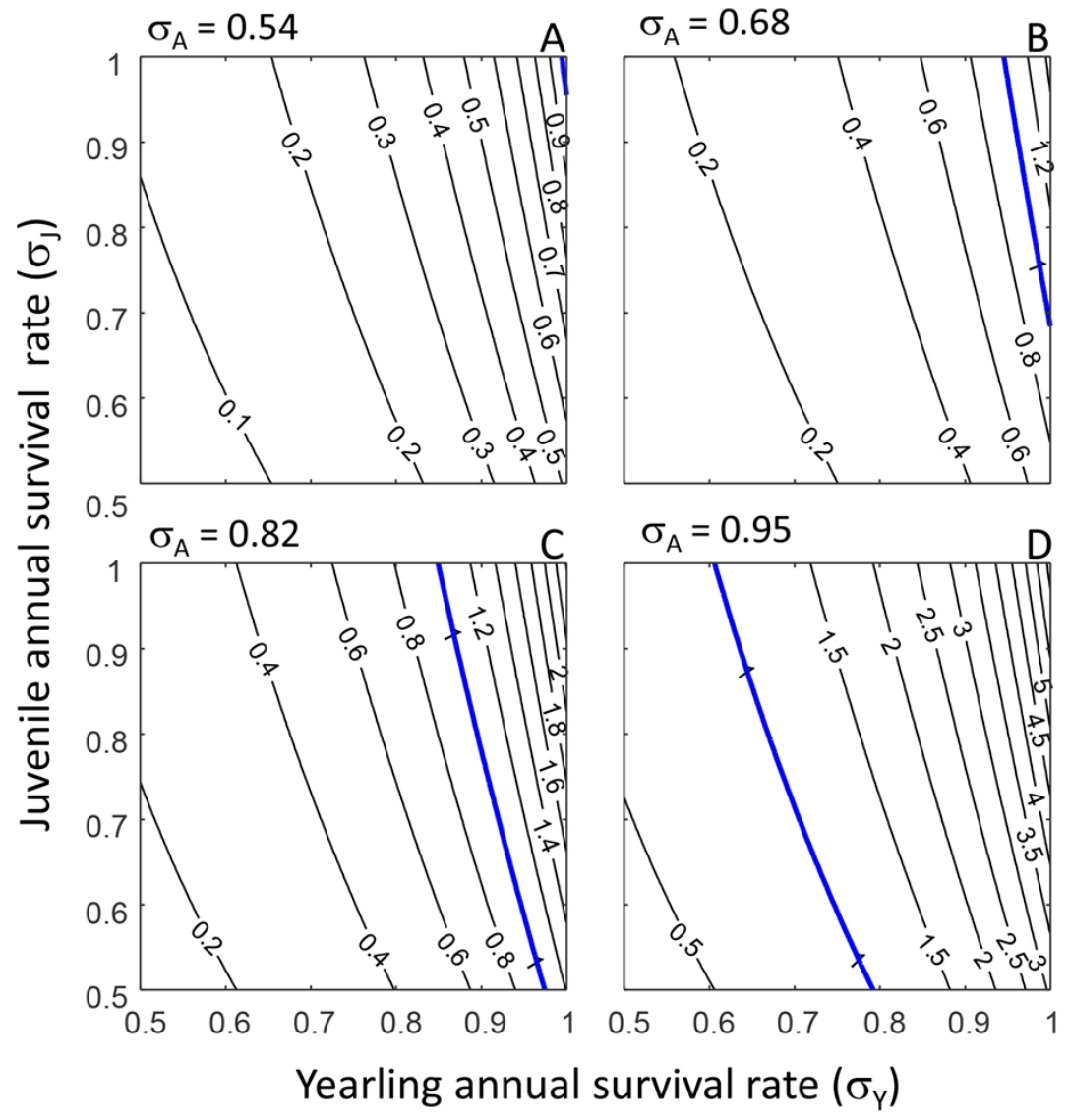

626

627 Figure 3 Mean lifetime reproductive success. Predicted lifetime reproductive success $\left(\mathrm{R}_{0}\right)$ in

628 relation to yearling annual survival rate $\left(\sigma_{\mathrm{Y}}\right)$ and juvenile annual survival rate $\left(\sigma_{\mathrm{J}}\right)$ shown for

629 each of four values of adult annual survival rate $\left(\sigma_{\mathrm{A}}\right): \sigma_{\mathrm{A}}=0.54$ (80\% of observed rate) (A); $\sigma_{\mathrm{A}}$

$630=0.68\left(\right.$ observed rate) $(\mathrm{B}) ; \sigma_{\mathrm{A}}=0.82(120 \%$ of observed rate $)(\mathrm{C})$; and $\sigma_{\mathrm{A}}=0.95(140 \%$ of

631 observed rate) (D). In each panel, isoclines denote equal values of lifetime reproductive success,

$632 \mathrm{R}_{0}$. The blue line in each panel denotes population stability at $\mathrm{R}_{0}=1$; values higher than $\mathrm{R}_{0}=1$

633 denote increasing populations and value lower than $\mathrm{R}_{0}=1$ denote declining populations. 


\section{Cohort generation time}

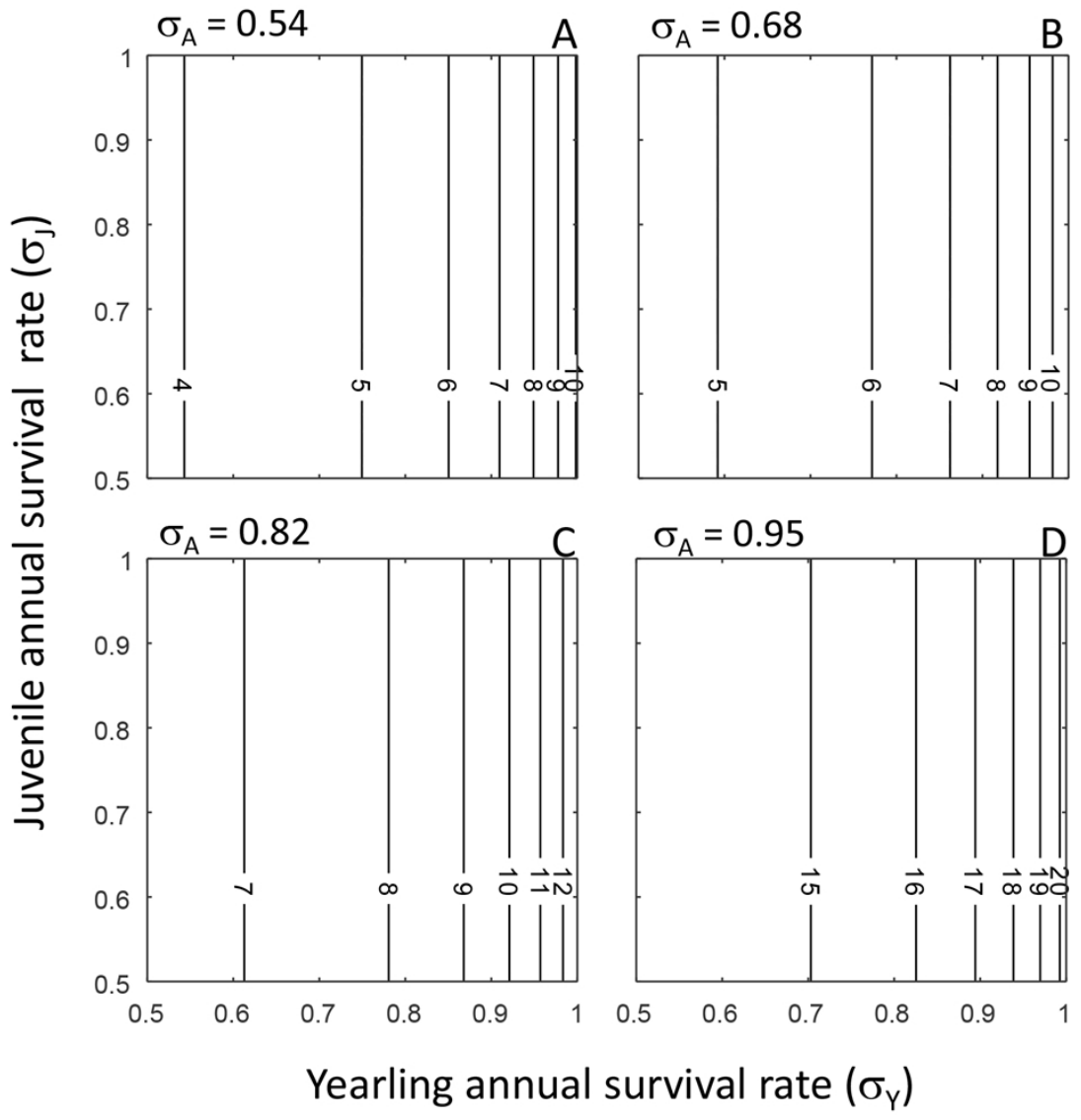

634

635 Figure 4 Cohort generation time. Predicted cohort generation time $\left(T_{c}\right)$ in relation to yearling 636 annual survival rate $\left(\sigma_{Y}\right)$ and juvenile annual survival rate $\left(\sigma_{J}\right)$ shown for each of four values of

637 adult annual survival rate $\left(\sigma_{\mathrm{A}}\right): \sigma_{\mathrm{A}}=0.54\left(80 \%\right.$ of observed rate) $(\mathrm{A}) ; \sigma_{\mathrm{A}}=0.68$ (observed rate)

638 (B); $\sigma_{\mathrm{A}}=0.82\left(120 \%\right.$ of observed rate) $(\mathrm{C})$; and $\sigma_{\mathrm{A}}=0.95$ (140\% of observed rate) (D). In each 639 panel, isoclines denote equal values of cohort generation time. 


\section{Population size projected over 10 years}

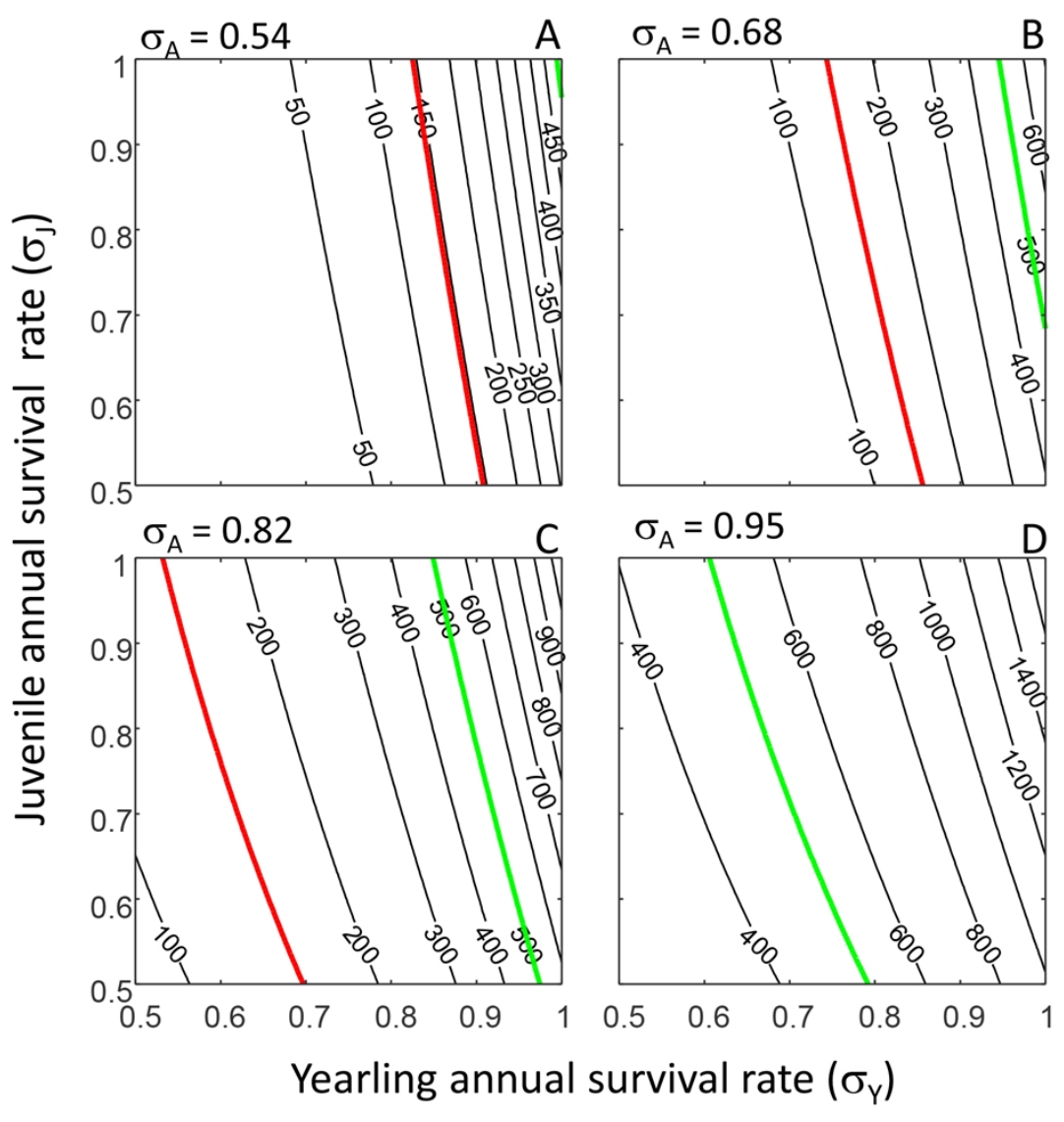

640

Figure 5 Population size projected over ten years. A population of 500 individuals is

642 projected over ten years using the predicted population growth rate $\lambda$ (Fig. 2). Projected

643 population sizes are shown in relation to yearling annual survival rate $\left(\sigma_{Y}\right)$ and juvenile annual

644 survival rate $\left(\sigma_{\mathrm{J}}\right)$ for each of four values of adult annual survival rate $\left(\sigma_{\mathrm{A}}\right): \sigma_{\mathrm{A}}=0.54(80 \%$ of

645 observed rate) $(\mathrm{A}) ; \sigma_{\mathrm{A}}=0.68$ (observed rate) $(\mathrm{B}) ; \sigma_{\mathrm{A}}=0.82\left(120 \%\right.$ of observed rate) $(\mathrm{C})$; and $\sigma_{\mathrm{A}}$

$646=0.95(140 \%$ of observed rate) (D). In each panel, isoclines denote equal values of projected

647 population size. The green line in each panel denotes population stability where the projected

648 population size is equal to the initial size of 500 individuals; above and below this line,

649 populations are projected to increase or decrease respectively. The red line in each panel depicts 
650 a population size of 149 individuals, which is equal to the lowest observed population size of 651 reef manta rays off the coast of Mozambique (Marshall, Dudgeon, \& Bennett, 2011b). 